\title{
VAGINAL VERSUS ABDOMINAL HYSTERECTOMY FOR BENIGN CONDITIONS
}

Garg P K*, Garg P*

\section{ABSTRACT}

Hysterectomy is the commonest gynaecological surgery performed in women. Present study involved 43 patients undergoing hysterectomy for benign condition. Out of $\mathbf{4 3}$ patients vaginal hysterectomy were performed in 26 cases and rest of the cases were performed by abdominal route. Out of 26 vaginal hysterectomy a case was converted into abdominal hysterectomy because of preoperative urinary bladder injury. Keeping all complications in mind we suggest that selective women requiring a hysterectomy for menstrual disorders from fibroid uterus or DUB may be offered a choice for vaginal hysterectomy.

Key Words: Hysterectomy, uterine leiomyoma.

\section{INTRODUCTION}

Hysterectomy is the commonest gynaecological surgery performed in women of the reproductive age group. Carlson ${ }^{1}$ indicated that commonest cause for hysterectomy is uterine leiomyoma.
Despite strong advocacy for the vaginal approach and guidelines to determine the route of hysterectomy, change in practice has not occurred and the major route of hysterectomy is still abdominal for benign gynaecological condition.

Patient characteristics and complication rates

* AllMS, New Delhi.

** NGMC, Nepal

Address for correspondence : $\quad$ Dr. Pradeep Kumar Garg

C - 38, Kamla Nagar

Agra (UP)

India - 282005

Email: pavangarg@epatra.com 